\title{
Práticas PEDAgógicas NA MEdIDA SOCIOEDUCATIVA DE INTERNAÇÃO DA FUNDAÇÃO CASA (SP): ANÁLISE DOCUMENTAL
}

\author{
PEDAGOGICAL PRACTICES IN THE SOCIO-EDUCATIONAL STANDARD OF \\ INTERNMENT AT FUNDAÇÃO CASA (SP): DOCUMENTAL ANALYSIS
}

\author{
Rivanil Rubens Nogueira \\ Doutorando em Ciências Sociais \\ Pontifícia Universidade Católica de São Paulo - PUC/SP \\ São Paulo, SP - Brasil \\ nil.poeta@hotmail.com \\ iD Almunita dos Santos Ferreira Pereira \\ Doutoranda em Ciências Sociais \\ Pontifícia Universidade Católica de São Paulo - PUC/SP \\ São Paulo, SP - Brasil \\ almunita134@gmail.com \\ Rita de Cássia Alves Oliveira \\ Doutora em Antropologia \\ Pontifícia Universidade Católica de São Paulo - PUC/SP \\ São Paulo, SP - Brasil \\ ritaalves@pucsp.br
}

Resumo: O presente artigo tem como objetivo identificar as práticas pedagógicas propostas na medida socioeducativa de internação para adolescentes em situação de privação de liberdade, com foco nos documentos estatais norteadores das condutas diárias, notadamente na Fundação Casa (São Paulo) e no Centro Socioeducativo Tamoios (São José dos Campos, SP). A análise documental, metodologia utilizada neste trabalho e realizada sob a perspectiva da legislação federal que trata do tema, o ECA e o SINASE, abarca os documentos produzidos nos níveis estadual, municipal e local, entre 2006 e 2019, tendo em vista a escolarização formal, arte e cultura, esporte e lazer, profissionalização.

social.

Palavras-chave: fundação casa; prática pedagógica; medida socioeducativa; adolescentes em conflito com a lei; análise documental.

Abstract: This article aims to identify the pedagogical practices proposed in the socio-educational practice of detention for adolescents in a situation of deprivation of freedom, with a focus on state documents that guide daily behavior, notably at Fundação Casa (São Paulo) and at Centro Socioeducativo Tamoios (São José dos Campos, SP). The documental analysis, methodology used in this work and carried out from the perspective of the federal legislation that deals with the subject, the ECA and the SINASE, encompasses the documents produced at the state, municipal and local levels, between 2006 and 2019, with a view to formal schooling, arts and culture, sports and leisure, professionalization.

Keywords: fundacao casa; pedagogical practice; socio-educational standards; teenagers in conflict with the law; documental analysis.

Para citar - ABNT NBR 6023:2018

NOGUEIRA, Rivanil Rubens; PEREIRA, Almunita dos Santos Ferreira; OLIVEIRA, Rita de Cássia Alves. Práticas pedagógicas na medida socioeducativa de internação da fundação casa (SP): análise documental. Cadernos de Pós-graduação, São Paulo, v. 20, n. 2, p. 37-49, jul./dez. 2021. Disponível em: https://doi.org/10.5585/cpg.v20n2.20136. 
Introdução

Os/as adolescentes em cumprimento de medida socioeducativa de internação têm os mesmos direitos que qualquer adolescente brasileiro/a e, por isso, devem dispor de proteção, educação formal, assistência médica, práticas culturais e esportivas etc., que garantam bem-estar, segurança e pleno desenvolvimento intelectual, físico, moral e cidadão. Os direitos de crianças e adolescentes, presentes no ECA, o Estatuto da Criança e do Adolescente (BRASIL, 1990), implicam em constante esforço por parte do Estado e da sociedade. Porém, quando se trata de adolescentes em conflito com a lei, não só a situação é mais complexa como as responsabilidades do Estado são redobradas e os resultados normalmente inadequados e questionáveis. Consequentemente, quando se desloca a discussão para as práticas pedagógicas adotadas por instituições de acolhimento de adolescentes em cumprimento de medida socioeducativa em regime de internação, tendo em vista o ensino formal e informal, observa-se que as práticas pedagógicas são o cerne do debate no campo da educação e o tema ganha outra dimensão.

Assim, este trabalho parte do pressuposto de que as práticas pedagógicas adotadas no cotidiano das instituições de cumprimento de medida socioeducativa de internação têm papel extremamente relevante no desenvolvimento e na formação dos/as adolescentes, conforme previsto no Estatuto da Criança e do Adolescente (ECA), como também na eficácia dos programas de execução dessa medida. Diante disso, quais seriam as diretrizes e orientações formais contidas nos documentos estatais que fundamentam as práticas pedagógicas desenvolvidas junto aos/às adolescentes em cumprimento de medida socioeducativa de internação?

O objetivo deste estudo é identificar, a partir do mapeamento dos principais documentos estatais, as proposições e orientações formais e estatais acerca das práticas pedagógicas a serem adotadas no cotidiano das unidades de cumprimento de medida socioeducativa de internação.

No presente trabalho, são tomados, como objeto de análise, documentos estatais (leis, portarias, cadernos de orientação etc.) produzidos entre 2006 e 2019, nos níveis estadual (Fundação Casa, São Paulo), municipal (São José dos Campos, SP) e local (Centro Socioeducativo Tamoios, SJC, SP). O interesse deste estudo assenta-se na Fundação Casa, entidade responsável pelo cumprimento de medidas socioeducativas no estado de São Paulo, e o Centro Socioeducativo Tamoios, localizado em São José dos Campos, no interior do estado.

Os procedimentos metodológicos aqui adotados seguem os caminhos da análise documental, de caráter qualitativo e exploratório, com foco nos documentos "de primeira mão" produzidos e publicados online pelos órgãos públicos responsáveis, sendo que o procedimento de coleta dos documentos envolveu fontes variadas, todas de caráter estatal, institucional, de acesso público e online. Segundo Antônio Carlos Gil (2002), a pesquisa documental, quando atrelada à 
dimensão histórica e à construção da memória de uma época, seja de um lugar, de um grupo social etc., possibilita a abordagem original do problema estudado, visando torná-lo mais explícito ou, ainda, analisá-lo em seus limites e ausências, registrando, a partir de dados empíricos, determinado momento histórico. Para este autor, "há que se considerar que os documentos constituem fonte rica e estável de dados. Como os documentos subsistem ao longo do tempo, tornam-se a mais importante fonte de dados em qualquer pesquisa de natureza histórica.” (GIL, 2002, p. 46). Os documentos foram considerados no âmbito da perspectiva crítica, que envolve a identificação dos contextos sociais e políticos nos quais foram produzidos, a natureza dos textos, assim como os autores e produtores dos documentos (CELLART, 2018).

A primeira etapa foi constituída a partir do mapeamento dos documentos estatais que norteiam e orientam as práticas pedagógicas a serem adotadas no cotidiano das atividades realizadas junto aos/as adolescentes em regime de internação, sendo tais documentos analisados com base no Estatuto da Criança e do Adolescente (ECA) e no SINASE, o Sistema Nacional de Atendimento Socioeducativo (BRASIL, 2012). No nível estadual, aqui considerando o estado de São Paulo, privilegiaram-se as portarias normativas pertinentes ao atendimento dos adolescentes, o Regimento Interno produzido pelo Departamento Jurídico da Fundação Casa, além dos Cadernos Orientadores elaborados pelas superintendências Pedagógica, da Saúde e da Segurança, documentos estes que incidem diretamente no Centro Socioeducativo Tamoios (SJC-SP); ainda no âmbito local, foram principalmente considerados o PPP, Plano Político Pedagógico (SÃO PAULO, 2017) e o Plano de Ação (SÃO PAULO, 2018a), ambos elaborados pela direção do Centro Socioeducativo Tamoios de São José dos Campos-SP.

Para garantir a representatividade dos documentos abordados, as fontes consultadas foram exploradas aplicando-se como critério básico de seleção, para além do período delimitado (20062019), as determinações ou orientações, quanto às práticas pedagógicas a serem adotadas no cotidiano das unidades de internação, notadamente nas seguintes atividades, práticas e áreas de atuação pedagógica: escolarização formal, arte e cultura, esporte e lazer e profissionalização. Essas práticas e áreas de atuação foram tomadas como categorias analíticas na construção do protocolo de análise e utilizadas como filtros na leitura dos documentos selecionados.

Este trabalho está estruturado em três partes: primeiramente, uma breve reflexão conceitual sobre práticas pedagógicas, assim como o contexto de cumprimento de medida socioeducativa; o segundo bloco, no qual se faz sucinta contextualização sobre a Fundação Casa e o Centro Socioeducativo Tamoios; e, a terceira parte, contendo a análise documental. 
Práticas pedagógicas e medida socioeducativa de internação

É possível pensar as práticas pedagógicas a partir de três questões fundamentais.

A primeira delas, "para que fazer”, está relacionada à intencionalidade da ação. Paulo Sérgio Negri (2008) salienta que a intencionalidade pedagógica está ligada à escolha de uma estratégia de ensino que considere os objetivos da educação, sabendo-se que, para efetivação das práticas pedagógicas, são necessários procedimentos e ações assertivas que contenham em seu processo a intencionalidade, conteúdos e formas de ação, bem como os recursos necessários.

A segunda questão, "o que fazer", refere-se aos conteúdos administrados, dos quais esperase que promovam o desenvolvimento de certas habilidades. Na perspectiva crítica, os conteúdos administrados devem corresponder à realidade das/os educandas/os. Nesse sentido, Paulo Freire e Ira Shor (1986) propõem a reflexão sobre a "educação bancária", aquela que é simplesmente depositária do conhecimento, ficando claro, na leitura desses autores, que o importante é o desenvolvimento das habilidades de crítica e reflexão, fundamentadas nos contextos e experiências cotidianas, buscando sempre a construção de ações conscientes e transformadoras.

A terceira questão, "como fazer", mostra a importância de uma didática crítica, que estruture pressupostos político-pedagógicos de seus conteúdos e dos procedimentos de ensino, evidenciando, e não distanciando, as contradições sociais existentes no processo educativo. Paulo Freire (1996) orienta, neste "como fazer", a construção do conhecimento como processo realizado por ambos os atores, professores/as e alunos/as, explicitando a necessidade de conhecer a realidade cotidiana dos/das estudantes e os contextos sociais nos quais estão inseridos, privilegiando as relações humanas acima de tudo. As práticas pedagógicas, assim, pressupõem a escolha de metodologias de trabalho, o que requer conteúdos pertinentes à realidade dos/as adolescentes, e a utilização de um tipo de didática que se aproxime dos perfis dos sujeitos, formas de abordagem dos temas discutidos, recursos utilizados etc. É necessário, portanto, criar estratégias que considerem os contextos sociais e culturais e os pontos de vista dos sujeitos-educandos ali envolvidos, o que pressupõe ação coletiva e dialógica entre educadores/as e educandos/as.

Paulo Freire aborda, em Educação e mudança (2013), o compromisso do/a profissional da educação com a sociedade, apontando que os/as educadores/as são agentes de transformação e, por conseguinte, condicionam os percursos de mudanças às reflexões sobre si mesmos/as e sobre as possíveis alterações estruturais que possam promover em prol da melhoria das condições sociais. Autores/a como Antônio Carlos Gomes da Costa (1999), Élcio Resmini Meneses (2006) e Liana de Paula (2017) apontam a importância das práticas pedagógicas na execução das medidas socioeducativas para que seja possível garantir aos/às adolescentes o desenvolvimento de suas capacidades individuais e o convívio adequado em sua comunidade. E, nesse contexto, faz-se 
necessário refletir sobre a relevância do educador social junto às instituições responsáveis por adolescentes em cumprimento de medidas socioeducativas, conforme aponta João Clemente de Souza Neto, quando afirma que "Pensar a formação do educador social significa contribuir com as instituições educacionais e cuidadoras de crianças e adolescentes em situação de vulnerabilidade e em conflito com a lei." (SOUZA NETO, 2007, p. 185). Ainda, segundo o mesmo autor, para além da formação do educador social e da reflexão sobre as práticas pedagógicas no âmbito da complexidade do acolhimento de adolescentes em conflito, como requer a lei, a construção de uma pedagogia social

Talvez seja essa uma das bases para elaboraç̃ão de uma pedagogia social que possa sistematizar os conhecimentos acumulados na história e colocá-los a favor dessa população. Se a comunidade científica e a sociedade problematizaram sobre quem são e como reagem aqueles que foram tachados de desviantes, pivetes, abandonados..., é porque já possuem condições para responder como desencadear um novo processo de socialização e humanização. Esse é o desafio da pedagogia social, que deve partir do pressuposto de que a noção de sujeito humano como aquele que faz o cotidiano e é por ele feito permanece controvertida e ainda distante de um consenso. (SOUZA NETO, 2007, p. 187).

\section{A Fundação Casa e o Centro Socioeducativo Tamoios (SP)}

A Fundação Casa (Centro de Atendimento Socioeducativo ao Adolescente) foi criada no Estado de São Paulo, em 2006, por meio da Lei 12.469/2009, em substituição à Fundação Estadual do Bem-Estar do Menor (Febem), de 1976, e definida como:

(...) instituição vinculada à Secretaria de Estado da Justiça e da Defesa da Cidadania, tem a missão primordial de aplicar medidas socioeducativas de acordo com as diretrizes e normas previstas no Estatuto da Criança e do Adolescente (ECA) e no Sistema Nacional de Atendimento Socioeducativo (SINASE). ${ }^{1}$

O Boletim Estatístico publicado semanalmente pelo Núcleo de Produção de Informações Estratégicas (Nuprie), da Fundação Casa, informa que, em 27 de dezembro de 2019, havia 6.792 adolescentes nos programas de atendimento da instituição, sendo 6.414 em regime de internação (incluindo internação provisória e sanção) ${ }^{2}$. De acordo com o governo do estado de São Paulo, durante todo o ano de 2018, a Fundação Casa prestou atendimento socioeducativo a 25.479 adolescentes, quase a metade deles/as apreendidos/as por tráfico de drogas e, um terço, por roubo qualificado ${ }^{3}$.

${ }^{1}$ Cf. Portal da Fundação Casa. Disponível em: <http://www.fundacaocasa.sp.gov.br/View.aspx?title=a-funda\%C3\%A7\%C3\%A3o\&d=10>. Acesso em: 16 jun. 2020.

${ }^{2}$ CF. Boletim Estatístico Fundação CASA, SP. Disponível em: <https://transparencia.fundacaocasa.sp.gov.br/index.php/boletins-2019/> Acesso em: 02 set. 2021

${ }^{3}$ CF. Disponível em: <https://www.saopaulo.sp.gov.br/sala-de-imprensa/release/fundacao-casa-faz-balanco-de-2018/>. Acesso em: 16 jun 2020. 
O Centro Socioeducativo Tamoios está situado no município de São José dos Campos, no estado de São Paulo, às margens da Rodovia Presidente Dutra, no Vale do Paraíba, um dos maiores polos econômicos do país. Atende adolescentes do sexo masculino, tanto de São José dos Campos, quanto dos demais municípios do Vale do Paraíba e do Litoral Norte do Estado. Oferece o Programa de Internação e de Internação Provisória (duração de 45 dias) para jovens aos quais foi atribuído cometimento de ato infracional. Conforme planilhas mensais do Centro Tamoios, 469 adolescentes estiveram internos na instituição no ano de 2019, considerando adolescentes que cumpriram medida de internação e de internação provisória (SÃO PAULO, 2020).

Análise documental: as orientações relativas às práticas pedagógicas nas medidas socioeducativas presentes nos documentos estatais

$\mathrm{Na}$ Fundação Casa, a escolarização formal é concebida como um direito básico, conforme preconizado no Art. 124, da Lei 8.069/90, constante no Estatuto da Criança e do Adolescente (ECA), que estabelece o direito à escolarização dos/das adolescentes privados/as de liberdade, garantindo, ainda, que a educação formal, na medida de privação de liberdade, esteja de acordo com os preceitos da Lei 9394/96 de Diretrizes Básicas da Educação (BRASIL, 1996). Quanto à política do SINASE, embora não tenha um artigo específico sobre a escolarização, contribui para reforçar e incluir o caráter educativo do atendimento socioeducativo e a obrigatoriedade da oferta da educação básica.

Em relação à educação formal nos Centros, os Cadernos Orientadores, como o Caderno Técnico Superintendência Pedagógica (SÃO PAULO 2010), o Caderno de Nutrição (SÃO PAULO, 2018), o Caderno de Avaliação Diagnóstica em Educação Física (SÃO PAULO, 2015), o Caderno do Serviço Social (SÃO PAULO, 2013) e Bases de Apoio Técnico para Psicologia na Fundação Casa (SÃO PAULO, 2012), bem como os Manuais, como o de Rotina e Procedimentos de Enfermagem (SÃO PAULO, 2014), Caderno de Nutrição (SÃO PAULO, 2018), e de Rotinas em Odontologia (SÃO PAULO, 2009), não apontam qualquer conduta específica, fazendo-se mister frisar que as ações realizadas pelas diferentes áreas interferem no processo educacional como um todo, deixando de sublinhar a necessidade da educação escolar como parâmetro de desenvolvimento dos e das adolescentes no cumprimento da medida socioeducativa.

Nesse sentido, o Regimento Interno (SÃO PAULO, 2012), regulamentado pela Portaria Normativa 224/2012, estabelece, no art. 46 e seus respectivos incisos (I-VII), que as assistências “educacional, cultural, esportiva e lazer devem assegurar a inclusão dos adolescentes, garantindo o livre acesso aos mesmos, de maneira obrigatória com a exigibilidade de que esse acesso seja de qualidade e de caráter transformador". Por outro lado, o controle disciplinar está explícito no 
Caderno Técnico Superintendência de Segurança e Disciplina,:conceitos, diretrizes e procedimentos (SÃO PAULO, 2010 ) que dispõe sobre o apoio do agente socioeducativo nas portas das salas de aula, a fim de garantir as condições de disciplina e segurança dos professores.

Analisando o Caderno Técnico Superintendência Pedagógica: conceitos, diretrizes e procedimentos (SÃO PAULO, 2014), verifica-se que, por mais que a construção do PPP presuma a participação efetiva de todos os profissionais, não está previsto o envolvimento específico das diferentes áreas no planejamento escolar. Depreende-se que a não participação de equipes multidisciplinares atrela a escolarização formal a uma prática engessada na Gestão Pedagógica de cada Centro.

Diante do contexto de escolarização, somente no Plano Político Pedagógico (PPP) de 2017, elaborado no Centro Tamoios, aparecem menções descritivas sobre a forma de organização do ensino formal na instituição, separando os adolescentes por séries, turmas e períodos. Entretanto, não foram registrados programas e projetos em relação à escolarização durante o ano escolar de 2018 e não se encontram evidências das ações pedagógicas realizadas e a forma de utilização dos espaços do Centro para as atividades em salas de aula, em salas de leitura, na biblioteca, nas oficinas e nos laboratórios, entre outros.

A pesquisa realizada por Fátima Cristina dos Santos (2019), que teve como objetivo compreender e analisar de que forma ocorre a educação formal em uma unidade da Fundação Casa, em São Bernardo do Campo, aponta várias fragilidades na instituição, entre elas, a falta de integração com outras medidas necessárias para a reinserção social dos adolescentes, a estrutura física inadequada, a insuficiência de materiais didáticos e o não oferecimento de formação específica aos docentes que ali atuam. Andrea Souza Marzochi (2014), ao realizar pesquisa em unidade da Fundação Casa, na cidade de Campinas, interior de São Paulo, ressalta que as chamadas salas de aula são espaços fechados com pesadas portas de ferro que apresentam uma fechadura para cadeado em sua parte externa e uma pequena abertura ao lado da porta, como uma janela estreita e comprida, a fim de facilitar a visualização dos agentes de segurança do que acontece lá dentro sem precisar mexer na porta, com lousas pintadas na parede e carteiras pequenas, do tipo universitária.

Em relação às atividades culturais e artísticas, verifica-se que o ECA preconiza, no artigo 124, inciso XII, que adolescentes privados/as de liberdade têm o direito de realizar atividades culturais, enquanto o SINASE não se refere diretamente à questão da cultura, apenas dispondo, no artigo $8^{\circ}$, que os Planos de Atendimento Socioeducativo deverão, obrigatoriamente, prever ações articuladas com a rede de atendimento, incluindo a área cultural. 
Para tanto, a Portaria 012/2000 (SÃO PAULO, 2000) regulamenta, em nível estadual, as saídas dos adolescentes para participação dos eventos culturais no meio externo. Todavia, mais do que realizar essas atividades, o importante é garantir, conforme o art. 46 do Regimento Interno (SÃO PAULO, 2012), o acesso a fontes de cultura que apoiem e estimulem as diferentes manifestações culturais e a liberdade de criação.

Dada a importância da arte e da cultura na medida socioeducativa, o Caderno Avaliação Diagnóstica em Educação Física (SÃO PAULO, 2015), orienta sobre a necessidade do estímulo para a participação do/a adolescente em atividades como música, dança, expressão corporal etc. Por outro lado, o Caderno Conceitos, Diretrizes e Procedimentos da Superintendência de Segurança (SÃO PAULO, 2014), nada menciona a respeito da arte e da cultura, embora faça parte das atribuições nele descritas a organização da segurança em todos os momentos, incluindo as atividades culturais. Já os Manuais e Cadernos da Área da Saúde - como o Manual de rotinas e procedimentos de Enfermagem (SÃO PAULO, 2014), Manual de rotinas em Odontologia (SÃO PAULO, 2009), Caderno de Nutrição (SÃO PAULO, 2018), Cadernos de Base de Apoio Técnico da Psicologia (SÃO PAULO, 2013) e do Serviço Social (SÃO PAULO, 2012) - não definem a importância e a intervenção nesse tipo de prática que a instituição valoriza como participação protagonista dos/as adolescentes.

Por outro lado, as indicações das oficinas de arte e cultura a serem realizadas no Centro Tamoios não aparecem com ênfase no Plano de Ação (SÃO PAULO, 2018a) e no PPP (SÃO PAULO, 2017), apenas são citadas como parte da programação das atividades no referido ano de 2017. Percebe-se que a não articulação e o desconhecimento do detalhamento das atividades entre as equipes, bem como alguns modelos disciplinares instituídos, que ainda se perpetuam na Fundação Casa, reverberam nos resultados propostos nas atividades socioculturais.

Nitiren Queiroz Castro e Marisa Irene Siqueira Castanho (2013) descrevem, a partir de abordagem foucaultiana, experiências nas atividades de ensino/aprendizagem de dança na Fundação Casa e trazem contribuições significativas, quando destacam que, em unidades nas quais a disciplina é demasiadamente rígida, há adolescentes com dificuldades de executar movimentos amplos e, em alguns casos, os adolescentes não conseguem soltar os braços, tendo as mãos voltadas para trás o tempo todo.

Para a realização das práticas de esporte e lazer, obedecendo os determinantes do capítulo IV, do ECA, e do Art. $8^{\circ}$, do SINASE, que estabelecem o direito à prática de esporte e lazer, a Fundação Casa realiza parcerias com as Secretarias de Cultura e Esporte e Lazer, apoiada em seu Regimento Interno que, em seu Art. 46, garante tais atividades com fins educacionais e inclusivos. 
Para tanto, o próprio Regimento prescreve, no art. 20, inciso III, a participação em passeios, atividades culturais ou esportivas fora do Centro de Atendimento.

Ainda, é evidente, no Caderno de Avaliação Diagnóstica de Educação Física (SÃO PAULO, 2015), a orientação para a prática esportiva que ultrapasse a mera preparação física, mas que contemple os cuidados com a saúde, o desenvolvimento cognitivo e, acima de tudo, o estabelecimento de um processo de interação social capaz da promoção de valores humanos necessários no convívio coletivo, como o respeito, a ética, a moral etc.

Todavia, os Cadernos Orientadores de Apoio da Psicologia (SÃO PAULO, 2012), do Serviço Social (SÃO PAULO, 2013) e Caderno de Nutrição (SÃO PAULO, 2018), assim como os Manuais de rotinas e procedimentos de Enfermagem (SÃO PAULO, 2014) e o Caderno de rotinas em Odontologia (SÃO PAULO, 2009), não citam a prática das atividades esportivas e de lazer. Já no tocante à disciplina, o Caderno Conceitos, Diretrizes e Procedimentos da Superintendência de Segurança e Disciplina (SÃO PAULO, 2014), esclarece e está previsto que todas as práticas esportivas e de lazer devem ser supervisionadas pelos agentes de apoio socioeducativo, a atenção e o controle referentes a esses momentos, principalmente nas saídas externas dos adolescentes.

Contudo, é interessante observar que os estímulos individuais fazem parte do discurso institucional, e até estão previstos como a normativa no Regimento Interno (SÃO PAULO, 2012 a), Art. 18. Porém, não consta, no PPP e nos Planos de Ação, qualquer referência quanto à sua organização nem são apresentadas as possíveis atividades externas a serem realizadas com os adolescentes.

No tocante à profissionalização, o ECA estabelece, no art. 69, o direito dos/as adolescentes à profissionalização e à proteção no trabalho e, combinado com art. 124, inclui os/as adolescentes privados de liberdade; e o SINASE, nos artigos. 76 a 79, também estabelece o direito à profissionalização e que, em conjunto com o Regimento Interno, em seu artigo. 46, objetiva possibilitar aos adolescentes o desenvolvimento de competências e habilidades básicas, oferecendo aprendizado profissional conforme suas demandas e o mercado de trabalho, todavia nenhuma Portaria faz menção específica a esse respeito.

Conquanto a proposta institucional, vislumbrada no Caderno Técnico da Superintendência Pedagógica (2010, p. 37), busque adaptar a preparação dos/as adolescentes no campo profissional aos limites de espaço, de tempo e de condições estruturais que os Centros Socioeducativos oferecem, e que, os documentos institucionais afirmam que todas as atividades realizadas com os/as adolescentes têm caráter interdisciplinar, não é possível perceber o mesmo teor nos demais Cadernos Orientadores nas áreas da saúde, psicossocial e segurança. 
O PPP da Fundação Casa Tamoios (2017) elucida sobre a prática da profissionalização básica com os adolescentes no Centro Tamoios, no entanto, o Plano de Ação nada menciona sobre tal feito nem existem indicações sobre os cursos realizados.

Nessa esteira, a pesquisa de mestrado realizada por Camila Marcondes Massaro (2010) sobre a preparação para o trabalho e as oficinas profissionalizantes na Fundação Casa, do município de Araraquara, conclui:

(...) entendemos que a formação proporcionada nas oficinas acaba contribuindo para a manutenção do status quo, no sentido de que os adolescentes são treinados para continuar ocupando papéis subalternos na esfera da produção. Nenhum incentivo é dado, nas oficinas profissionalizantes, para que os adolescentes possam - ao menos idealizar, quiçá entender como possibilidade concreta - ser "empreendedores", conforme termo corrente. (MASSARO, 2010, p. 225).

\section{Considerações finais}

Este trabalho buscou identificar, a partir de análise documental, as práticas pedagógicas presentes em documentos oficiais estatais em relação à medida socioeducativa de internação na Fundação Casa no Estado de São Paulo.

A primeira observação que se pode fazer está relacionada à intencionalidade presente nos documentos institucionais, que buscam se adequar ao caráter educativo previsto nas Leis 8069/90 (ECA) e 12.594/12 (SINASE). A questão da escolarização, um dos eixos considerado fundamental na medida socioeducativa, muito embora não esteja presente em todos os documentos oficiais. As orientações contidas nos documentos que norteiam as práticas pedagógicas no contexto socioeducativo enfatizam a intervenção no comportamento delituoso do/da adolescente, valendose de estratégias focadas nas atividades de escolarização formal, arte e cultura, profissionalização e esporte possibilitando, assim, que adolescentes em situação de privação de liberdade possam reconfigurar suas trajetórias de vida distante do meio infracional.

Os resultados apontaram a sobreposição do olhar da disciplina e da segurança que mantémse como artifícios reguladores, engessando e fragmentando os objetivos e as premissas pedagógicas.

A pesquisa apontou que os documentos orientadores das práticas pedagógicas produzidos pela Fundação Casa não apresentam plena sintonia entre si, dificultando, possivelmente, a emergência de propostas de práticas pedagógicas articuladas entre todas as equipes das unidades. 


\section{Referências}

BRASIL. Lei ñ 8.069, de 13 de julho de 1990. Dispõe sobre o Estatuto da Criança e do Adolescente e dá outras providências. Disponível em: http://www.planalto.gov.br/ccivil_03/LEIS/L8069.htm. Acesso em: 12 jan. 2019.

BRASIL. Lei ñ 9.394, de 20 de dezembro de 1996. Estabelece as diretrizes e bases da educação nacional. Disponível em: http://www.planalto.gov.br/ccivil_03/leis/19394 .htm. Acesso em: 10 fev. 2019.

BRASIL. Lei $n^{\circ} 12.594$, de 18 de janeiro de 2012. Institui o Sistema Nacional de Atendimento Socioeducativo (SINASE) e dá outras providências. Disponível em:

http://www.planalto.gov.br/ccivil_03/_Ato2011-2014/2012/Lei/L12594.htm. Acesso em: 12 jan. 2019.

CASTRO, Nitiren Queiroz; CASTANHO, Marisa Irene Siqueira. Autoria entre muros e grades: um olhar psicopedagógico sobre o ensino/aprendizagem de dança na Fundação CASA. Rev. Psicopedagogia, ed. 92, v. 30, São Paulo, pp. 129-141, 2013.

CELLARD, André. A análise documental. In: POUPART, Jean. A Pesquisa Qualitativa: enfoques epistemológicos e metodológicos. Petrópolis: Vozes, 2018, pp. 295-316.

COSTA, Antônio Carlos Gomes da. A presença da pedagogia: teoria e prática da ação socioeducativa. São Paulo: Global/ Instituto Ayrton Senna, 1999.

FREIRE, Paulo. Pedagogia do oprimido. São Paulo: Paz e Terra, 1996.

FREIRE, Paulo. Educação e mudança. São Paulo: Paz e Terra, 2013.

FREIRE, Paulo; SHOR, Ira. Medo e ousadia: o cotidiano do Professor. São Paulo: Paz e Terra, 1986.

GIL, Antônio Carlos. Como elaborar projetos de pesquisa. São Paulo: Atlas, 2002.

MARZOCHI, Andréa Souza. História de vida dos jovens da Fundação Casa: o lugar da escola nessas vidas. Campinas, 2014. Dissertação de Mestrado em Educação. Universidade Estadual de Campinas Unicamp.

MASSARO, Camila Marcondes. Preparação para o Trabalho na Fundação Casa: as oficinas profissionalizantes. Cad. Cedes, Campinas, v. 30, n. 81, p. 219-232, mai.-ago. 2010.

MENESES, Elcio Resmini. O Ministério Público e as medidas socioeducativas: uma reflexão jurídicopedagógica. Porto Alegre, 2006. Dissertação de Mestrado em Educação, - Universidade Federal do Rio Grande do Sul.

NEGRI, Paulo Sérgio. Comunicação didática: A intencionalidade pedagógica como estratégia de ensino. Módulo I. Londrina: LABTED/UEL, 2008.

PAULA, Liana de. Punição e cidadania: adolescentes e liberdade assistida na cidade de São Paulo. São Paulo: Alameda, 2017. 
SANTOS, Fátima Cristina dos. Entre muros grades, escola e privação de liberdade: um diálogo com docentes da Fundação Casa de São Bernardo do Campo. São Paulo, 2019. Dissertação de Mestrado em Educação. Universidade Metodista de São Paulo.

SÃO PAULO. Avaliação Diagnóstica em Educação Física. Gerência de Educação Física e Esporte. Fundação Casa. São Paulo, 2015. Disponível em https://www.fundacaocasa.sp.gov.br/wpcontent/uploads/2019/12/pdf_aval-diag-educ-fisica-divulgacao-eletronica-Out-15.pdf

SÃO PAULO. Caderno Técnico/Superintendência Pedagógica: Conceitos, Diretrizes, Procedimentos. Superintendência Pedagógica. Fundação Casa. São Paulo, 2010.

SÃO PAULO. Caderno Conceitos, Diretrizes e Procedimentos. Superintendência de Segurança e Disciplina Fundação Casa, 2014.

SÃO PAULO. Bases de Apoio Técnico para Psicologia na Fundação Casa. Superintendência de Saúde. Gerência Psicossocial. Fundação Casa. São Paulo, 2012. Disponível em https://fundacaocasa.sp.gov.br/wp-content/uploads/2019/12/pdf_psicologia_final.pdf

SÃO PAULO. Bases de Apoio Técnico para o Serviço Social. Superintendência de Saúde. Gerência Psicossocial. Fundação Casa. São Paulo, 2013.

SÃO PAULO. Manual de Rotinas e Procedimentos de Enfermagem. Superintendência de Saúde. Gerência de Saúde. Fundação Casa. São Paulo, 2014.

SÃO PAULO. Manual de Rotinas em Odontologia. Superintendência de Saúde. Gerência Psicossocial. Fundação Casa. São Paulo, 2009.

SÃO PAULO. Regimento Interno. Fundação Casa. São Paulo, 2012a.

SÃO PAULO. Caderno Orientador de Nutrição. Superintendência de Saúde. Gerência de Saúde. Fundação Casa. São Paulo, 2018. Disponível em https:/ / fundacaocasa.sp.gov.br/wpcontent/uploads/2021/04/Saude_Orientador_Nutricao.pdf

SÃO PAULO. Plano Político Pedagógico. Centro Socioeducativo Tamoios. Fundação Casa. São José dos Campos, 2017.

SÃO PAULO. Plano de Ação. Centro Socioeducativo Tamoios. Fundação Casa. São José dos Campos, 2018a.

SÃO PAULO. Planilhas Mensais. Centro Socioeducativo Tamoios. Fundação Casa. São José dos Campos, 2020.

SÃO PAULO. Centro de Atendimento Socioeducativo ao Adolescente. Portaria Normativa 012/00. São Paulo, 2000. Disponível em: http://www.fundacaocasa.sp.gov.br/files/portarias/62.pdf. Acesso em: 22 fev. 2021.

SÃO PAULO. Lei 12469. Altera a denominação da Fundação Estadual do Bem-Estar do Menor. São Paulo, 2006. Disponível em: https://www.al.sp.gov.br/repositorio/legislacao/lei/2006/lei12469-22.12.2006.html. Acesso em: 19 jan. 2020. 
SÃO PAULO. Núcleo de Produção de Informações Estratégicas. Fundação Casa, 2019. Disponível em: www.fundacaocasa.sp.gov.br/up.ashx?f=boletins/Boletim2/038..pdf/. Acesso em: 20 abr. 2021.

SOUZA NETO, João Clemente. Repercussões da doutrina de proteção integral na formação dos educadores sociais. XIV Jornadas de Investigación y Tercer Encuentro de Investigadores en Psicología del Mercosur. Facultad de Psicología - Universidad de Buenos Aires, Buenos Aires, 2007. 